\title{
Simulating secondary organic aerosol in a regional air quality model using the statistical oxidation model - Part 1: Assessing the influence of constrained multi-generational ageing
}

\author{
S. H. Jathar ${ }^{1,2}$, C. D. Cappa ${ }^{2}$, A. S. Wexler ${ }^{2}$, J. H. Seinfeld ${ }^{3}$, and M. J. Kleeman ${ }^{2}$ \\ ${ }^{1}$ Mechanical Engineering, Colorado State University, Fort Collins CO, USA \\ ${ }^{2}$ Civil and Environmental Engineering, University of California, Davis CA, USA \\ ${ }^{3}$ Chemical Engineering, California Institute of Technology, Pasadena CA, USA
}

Correspondence to: C. D. Cappa (cdcappa@ucdavis.edu)

and M. J. Kleeman (mjkleeman@ucdavis.edu)

Received: 19 August 2015 - Published in Atmos. Chem. Phys. Discuss.: 24 September 2015

Revised: 8 January 2016 - Accepted: 13 January 2016 - Published: 26 February 2016

\begin{abstract}
Multi-generational oxidation of volatile organic compound (VOC) oxidation products can significantly alter the mass, chemical composition and properties of secondary organic aerosol (SOA) compared to calculations that consider only the first few generations of oxidation reactions. However, the most commonly used state-of-thescience schemes in 3-D regional or global models that account for multi-generational oxidation (1) consider only functionalization reactions but do not consider fragmentation reactions, (2) have not been constrained to experimental data and (3) are added on top of existing parameterizations. The incomplete description of multi-generational oxidation in these models has the potential to bias source apportionment and control calculations for SOA. In this work, we used the statistical oxidation model (SOM) of Cappa and Wilson (2012), constrained by experimental laboratory chamber data, to evaluate the regional implications of multi-generational oxidation considering both functionalization and fragmentation reactions. SOM was implemented into the regional University of California at Davis / California Institute of Technology (UCD/CIT) air quality model and applied to air quality episodes in California and the eastern USA. The mass, composition and properties of SOA predicted using SOM were compared to SOA predictions generated by a traditional two-product model to fully investigate the impact of explicit and self-consistent accounting of multigenerational oxidation.
\end{abstract}

Results show that SOA mass concentrations predicted by the UCD/CIT-SOM model are very similar to those predicted by a two-product model when both models use parameters that are derived from the same chamber data. Since the twoproduct model does not explicitly resolve multi-generational oxidation reactions, this finding suggests that the chamber data used to parameterize the models captures the majority of the SOA mass formation from multi-generational oxidation under the conditions tested. Consequently, the use of low and high $\mathrm{NO}_{x}$ yields perturbs SOA concentrations by a factor of two and are probably a much stronger determinant in 3-D models than multi-generational oxidation. While total predicted SOA mass is similar for the SOM and two-product models, the SOM model predicts increased SOA contributions from anthropogenic (alkane, aromatic) and sesquiterpenes and decreased SOA contributions from isoprene and monoterpene relative to the two-product model calculations. The SOA predicted by SOM has a much lower volatility than that predicted by the traditional model, resulting in better qualitative agreement with volatility measurements of ambient OA. On account of its lower-volatility, the SOA mass produced by SOM does not appear to be as strongly influenced by the inclusion of oligomerization reactions, whereas the two-product model relies heavily on oligomerization to form low-volatility SOA products. Finally, an unconstrained contemporary hybrid scheme to model multi-generational oxidation within the framework of a two-product model in which ageing reactions are added on top of the existing two-product 
parameterization is considered. This hybrid scheme formed at least 3 times more SOA than the SOM during regional simulations as a result of excessive transformation of semivolatile vapors into lower volatility material that strongly partitions to the particle phase. This finding suggests that these hybrid multi-generational schemes should be used with great caution in regional models.

\section{Introduction}

Organic aerosol (OA) is generally the dominant component of submicrometer-sized atmospheric particulate matter (Jimenez et al., 2009), which plays an important role in the energy budget of the earth (Pachauri et al., 2014) and the health effects of air pollution (Bernstein et al., 2004). Despite its prominence, $\mathrm{OA}$ is the least understood component of atmospheric aerosol. Large-scale chemical transport models are the essential tool to simulate concentration distributions, which are needed to form strategies to mitigate, the climate and health impacts of atmospheric aerosols.

$\mathrm{OA}$ is a complex mixture of thousands of different compounds that have a wide range of properties (Goldstein and Galbally, 2007). OA can be directly emitted to the atmosphere in particulate form (so-called primary organic aerosol; POA) or it can be formed in situ by the oxidation of volatile organic compounds (VOCs) to yield lower volatility products that condense into the aerosol phase, so-called secondary organic aerosol (SOA). This latter route is generally the predominant one to form OA. Continuous oxidation of VOCs and their oxidation products yields a broad range of products, including those that have intermediate and low volatility. The importance of such multi-generational oxidation on SOA production has been widely established in laboratory chamber experiments (Chacon-Madrid et al., 2010, 2013; Yee et al., 2013; Donahue et al., 2012; Chhabra et al., 2011; Henry and Donahue, 2012). Multi-generational oxidation includes the initial formation of oxidized products of lower volatility as well as the loss of SOA mass after initial formation owing to fragmentation reactions. For example, experiments performed with the potential aerosol mass (PAM) reactor, which aims to simulate prolonged VOC oxidation, are always associated with formation followed by destruction of OA mass (Lambe et al., 2012). Simulations that capture this behavior require inclusion of multi-generational oxidation. In addition to altering predicted SOA mass, inclusion of multi-generational oxidation is expected to alter the oxidation state of OA, which has important repercussions for OA properties (e.g., water uptake, toxicity) (Jimenez et al., 2009).

Traditionally, models of SOA formation in chamber experiments have represented SOA formation from VOCs using two to four surrogate products per VOC, the yields for which have been parameterized to reproduce observed levels of SOA (Odum et al., 1996). These models generally assume that the surrogate products are non-reactive (i.e., do not undergo multi-generational oxidation). These models, whether implemented in two-product or volatility basis set (VBS) forms (Donahue et al., 2006), generally under-predict ambient concentrations of SOA (Carlton et al., 2010). Some models have used simple chemical schemes to mimic the effects of multi-generational oxidation. While these schemes differ in their details, in essence, they assume that the vapors and the products of each surrogate traditional VOC species react with the hydroxyl radical $(\mathrm{OH})$ to form lower volatility products (Robinson et al., 2007; Pye and Seinfeld, 2010; Baek et al., 2011). Such ageing schemes to account for multi-generational oxidation of traditional VOC products share similarities with reaction schemes applied to the oxidation of intermediate-volatility organic compounds (IVOCs) and POA vapors (Robinson et al., 2007). Note that oxidation of IVOCs and POA vapors is assumed to proceed only through these ageing-type reactions, whereas oxidation of the semi-volatile products of traditional VOC precursors is an augmentation to the existing two-product or VBS parameterization. Models that include these ageing schemes predict SOA mass concentrations that close the gap with measured ambient concentrations of OA mass. As a result, over the past 5 years, both research and regulatory groups have incorporated these schemes into their 3-D models [e.g., Environmental Protection Agency's Community Multiscale Air Quality Model (CMAQ) (Koo et al., 2014), PMCAMx (Murphy and Pandis, 2009; Tsimpidi et al., 2010), WRF-CHEM (Ahmadov et al., 2012; Lane et al., 2008; Tsimpidi et al., 2010)]. These first-order SOA schemes have three major mechanistic drawbacks. First, they typically do not account for laboratory evidence of fragmentation of oxygenated organic molecules that can lead to decreases in SOA concentrations (Chacon-Madrid and Donahue, 2011; Henry and Donahue, 2012). Second, they assume that the multi-generational oxidation of products of different anthropogenic VOCs (e.g., alkanes vs. aromatics) or different biogenic VOCs (e.g., isoprene vs. monoterpenes) share the same reaction mechanism. Finally (and most importantly), these schemes remain under-unconstrained in that they have not been rigorously tested against measurements of multi-generational products (or classes of products) under realistic ambient conditions, and they are typically added on top of existing parameterizations. These concerns apply specifically to the multigenerational oxidation schemes that are commonly applied to traditional VOCs, but these are also relevant to the oxidation schemes associated with IVOCs and POA vapors. Chemically explicit models have seldom been used in 3-D modeling (e.g., Johnson et al., 2006; Chen et al., 2006; Ying and $\mathrm{Li}, 2011$ ) due to their heavy computational burden, although some studies have used reduced complexity forms for 3-D modeling (e.g., Utembe et al., 2011; Lin et al., 2012) or have implemented them for box modeling studies (e.g., LeeTaylor et al., 2011). 
In this work, we use the statistical oxidation model (SOM) of Cappa and Wilson (2012) to model the multi-generational oxidation reactions inherent in SOA formation. The SOM provides an efficient framework to track the experimentally constrained chemical evolution and gas-particle partitioning of SOA using a carbon and oxygen grid. In Jathar et al. (2015), we detailed the coupling of the SOM with the gas-phase chemical mechanism SAPRC-11 (Carter and Heo, 2013) within the UCD/CIT regional air quality model and used the new model to make predictions over the South Coast Air Basin (SoCAB) in California and the eastern United States. Here, we use the UCD/CIT-SOM model to investigate the influence of constrained multi-generational oxidation on the mass concentrations and properties of SOA and contrast those results against predictions from a traditional two-product model and an unconstrained multi-generational oxidation model.

\section{Model description and simulations}

\subsection{Air quality model}

The UCD/CIT air quality model is a regional chemical transport model (CTM) (Kleeman and Cass, 2001) used here to simulate SOA formation for two geographically distinct domains and time periods: (1) the state of California simulated at a grid resolution of $24 \mathrm{~km}$ followed by a nested simulation over the SoCAB at a grid resolution of $8 \mathrm{~km}$ from 20 July to 2 August 2005, and (2) the eastern half of the USA simulated at a grid resolution of $36 \mathrm{~km}$ from $20 \mathrm{Au}-$ gust to 2 September 2006. Details about the latest version of the UCD/CIT model are provided in Jathar et al. (2015) and summarized in Table S1 in the Supplement. Briefly, anthropogenic emissions for California were based on the California Regional PM10/PM2.5 Air Quality Study (CRPAQS) inventory of 2000 but scaled to match conditions in 2005. FINN (Fire Inventory for National Center for Atmospheric Research) (Wiedinmyer et al., 2011) and MEGAN (Model of Emissions of Gases and Aerosols from Nature) (Guenther et al., 2006) were used to calculate wildfire and biogenic emissions in California. Anthropogenic and wildfire emissions for the eastern USA were based on the $2005 \mathrm{Na}$ tional Emissions Inventory (NEI), and biogenic emissions were estimated using BEIS (Biogenic Emissions Inventory System) version 3. Hourly meteorological fields were generated using the Weather Research and Forecasting (WRF) v3.4 model (www.wrf-model.org). National Center for Environmental Protection's NAM (North American Mesoscale) analysis data were used to set the initial and boundary conditions for WRF. Gas- and particle-phase initial and hourly varying boundary conditions were based on the results from the global model MOZART-4/NCEP (Emmons et al., 2010). Gas-phase chemistry was modeled using SAPRC-11. In all simulations, POA was treated as non-volatile, yet absorp- tive, as per the treatment in the regulatory Community Multiscale Air Quality (CMAQ) version 4.7 model (Carlton et al., 2010). As such, contributions of semi-volatile and intermediate volatility organic compound emissions (which are commonly assumed to originate from the evaporation of and co-emitted with POA) to the SOA burden were not considered in this study.

\subsection{SOA models}

Four types of SOA models are compared in this work: (1) a Base two-product model that is equivalent to the SOA model used in CMAQ and representative of SOA models used in most chemical transport (Carlton et al., 2010) and global climate models (Henze et al., 2008); (2) a modified version of the Base model, BaseM, which uses the two-product framework, but in which the SOA formation parameters were determined using newer chamber data; (3) a SOM model (Cappa and Wilson, 2012) in which multi-generational oxidation is accounted for through semi-explicit representation of progressive generations of gas-phase oxidation of the products and precursors of SOA, and which was parameterized based on the same data set as the BaseM model; (4) a cascading oxidation model, wherein ageing of semi-volatile products was accounted for a posteriori using ageing rates derived from separate experiments. All of the SOA models utilize fully dynamic gas-particle partitioning for OA species as in Kleeman and Cass (2001). The following sub-sections describe the four SOA models. To aid the reader, a conceptual schematic comparing various SOA models (e.g., 2-product, SOM, VBS) is provided in Fig. S1.

\subsubsection{Base}

The Base model simulated SOA formation as per the pathways and parameters in the CMAQ model version 4.7 (Carlton et al., 2010) from the following gas-phase precursors: long alkanes (ALK5), benzene (BENZENE), lowyield aromatics (ARO1), high-yield aromatics (ARO2), isoprene, monoterpenes (TRP1) and sesquiterpenes (SESQ). The species in parentheses are the model species representing those compounds in SAPRC-11 (the gas-phase chemical mechanism used here). The pathways considered include (1) oxidation of the above-mentioned precursors to form non-reactive semi-volatile products that partition into the particle-phase (Odum et al., 1996) (the so-called twoproduct model, where model parameters were previously determined from fitting chamber data); (2) acid enhancement of isoprene SOA (Surratt et al., 2007). SOA formation from aromatics is $\mathrm{NO}_{x}$ dependent; low levels of $\mathrm{NO}_{x}$ result in higher SOA formation and vice-versa. The Base model was extended to include particle-phase oligomerization (Kalberer et al., 2004), for which particle-phase semi-volatile components were converted to non-volatile components with $k_{\text {oligomer }}=9.6 \times 10^{-6} \mathrm{~s}^{-1}$. In summary, the Base model was 
run in two configurations, with and without oligomerization reactions: Base and Base-OLIG.

\subsubsection{Base modified}

The modified version of the Base model, termed BaseM was created to facilitate a true evaluation of multi-generational oxidation in a two-product model framework. The BaseM model: (1) used recent chamber data (Jathar et al., 2015) from California Institute of Technology to determine alternate two-product model parameters; and (2) did not include acid-catalyzed enhancement of isoprene SOA and oligomerization reactions. The two-product fit parameters and data sources are listed in Table S2. Note that the long alkane BaseM parameterization has been developed using experimental results for SOA formation from $n$-dodecane (Loza et al., 2014).

\subsubsection{Statistical oxidation model}

The SOM parameterizes multi-generational oxidation using a two-dimensional carbon-oxygen grid to track the evolution of gas- and particle-phase organic products arising from the oxidation of SOA precursors (Cappa and Wilson, 2012; Cappa et al., 2013; Zhang et al., 2014). This evolution through the SOM grid is VOC-specific and defined by six parameters: (P1-P4) yields of the four products that add 1, 2, 3 and 4 oxygen atoms, without fragmentation; (P5) the probability of fragmentation; and (P6) the decrease in vapor pressure (or volatility) of the species per addition of oxygen atom. Details of the implementation and parameterization of the SOM model in the UCD-CIT are presented in Jathar et al. (2015). Briefly, six SOM grids with precursorspecific parameter sets were used to represent SOA formation from the same precursor classes in the Base model. Parameter sets were separately determined from high $\mathrm{NO}_{x}$ (low yield) and low $\mathrm{NO}_{x}$ (high yield) chamber data as the $\mathrm{SOM}$ in its current configuration cannot yet account for continuous variation in $\mathrm{NO}_{x}$. The $\mathrm{SOM}$ parameters were completely determined from explicit fitting to chamber data where the number of fit data points greatly exceeded the number of fitting parameters (6). Thus, the SOM model will be referred to as constrained multi-generational oxidation. The SOM parameters and data sources are listed in Table S3.

The SOM model parameters used in the present study were determined without accounting for losses of vapors to chamber walls, which can lead to a substantial underestimation of the actual SOA formation potential of a given precursor (Matsunaga and Ziemann, 2010; Zhang et al., 2014). A companion paper evaluates vapor wall-loss effects on the SOM results (Cappa et al., 2015). The SOM parameter fits were derived using dynamic gas-particle partitioning assuming an accommodation coefficient of unity, which tends to minimize the influence of vapor wall loss (McVay et al., 2014), and thus represents a conservative lower bound of SOA for- mation. The SOM model was additionally extended to consider the influence of oligomerization reactions by allowing irreversible conversion of particle-phase SOM species into a single non-volatile species using the same $k_{\text {oligomer }}$ as in the Base model, referred to as SOM-OLIG. Oligomerization reactions were added a posteriori to the SOM model, i.e., oligomerization reactions were not included as part of the data fitting and parameter determination and are included in the present study only as a sensitivity case.

\subsubsection{Cascading oxidation model}

Additional simulations were performed using a contemporary multi-generational oxidation scheme, the cascading oxidation model (COM). The COM builds on the two-product Base model but allows for additional reaction of the semivolatile products using the scheme of Baek et al. (2011). Briefly, the two semi-volatile products from a given precursor react with $\mathrm{OH}$, with the highest volatility product converted into the lowest volatility product and the lowest volatility product converted to a non-volatile product (see Supplement section on Cascading Oxidation Model). Like most other schemes that have thus far been used to represent multi-generational oxidation of SOA from traditional VOCs in 3-D models (Lane et al., 2008), COM does not consider fragmentation reactions, is not fit or constrained to experimental data and adds these ageing reactions on top of an existing parameterization. The COM model will be referred to as unconstrained multi-generational oxidation.

\subsection{Simulations}

Table 1 lists the simulations performed in this work. We performed two simulations with the Base model (with and without oligomerization), two with the BaseM model (low and high yield), four with the SOM model (low and high yield and with oligomerization accounted for) and one with the COM model. These nine simulations were performed for both domains: SoCAB and the eastern USA. Simulations were performed for 19 days with the first 5 days used for spin-up. For the SoCAB, each simulated day using the SOM required approximately $4 \mathrm{~h}$ of elapsed time (on 40 Intel i53570 processor cores) so a 19-day episode was simulated in less than 4 days. For the eastern USA, each simulated day required approximately $9 \mathrm{~h}$ of elapsed time so a 19-day episode was simulated in about 8 days. The SOM simulations were approximately 4 times slower than the BaseM simulations on account of the large number of model species.

\section{Results}

\subsection{Base vs. BaseM}

Although the main focus of the present study is on understanding the role of multi-generational oxidation in SOA 
Table 1. Simulations performed in this work.

\begin{tabular}{ll}
\hline Simulation & Description \\
\hline Base & Equivalent to Carlton et al. (2010) without oligomerization \\
Base-OLIG & Equivalent to Carlton et al. (2010) \\
BaseM (low yield) & two-product model using new high $\mathrm{NO}_{x}$ data (low yield) \\
BaseM (high yield) & two-product model using new low $\mathrm{NO}_{x}$ data (high yield) \\
SOM (low yield) & New high $\mathrm{NO}_{x}$ data, no vapor wall losses \\
SOM (high yield) & New low NO $\mathrm{N}_{x}$ data, no vapor wall losses \\
SOM-OLIG (low yield) and & SOM with inclusion of oligomerization \\
SOM-OLIG (high yield) & Base-OLIG model with added ageing reactions \\
\hline
\end{tabular}

models, it is useful to begin by considering differences between the predictions from Base and BaseM (two-product parameters fit to more recent data sets). The 14-day averaged, precursor-resolved SOA concentrations at two sites in the SoCAB (Los Angeles: urban; Riverside: urban outflow) and at two sites in the eastern US (Atlanta: urban; Smoky Mountains: remote) from Base and BaseM are compared in Fig. 1. Base model predictions of total semi-volatile SOA concentrations (i.e., SOA exclusive of oligomers) at all four sites are similar to the BaseM (low-yield) model predictions that were parameterized using high- $\mathrm{NO}_{x}$ chamber data. This outcome is perhaps not surprising at Los Angeles, Riverside and Atlanta since these urban areas have higher $\mathrm{NO}_{x}$ levels and, correspondingly, the Base simulations effectively used high- $\mathrm{NO}_{x}$ parameters. While there are slight increases in SOA from some precursors and decreases from others, BaseM, in comparison to Base, predicted negligible contributions from alkane SOA. The general agreement between Base and BaseM (low yield) in rural/remote areas like the Smoky Mountains (where more than three-quarters of the SOA comes from terpene oxidation) also resulted from increases in SOA from some precursors and decreases from others. These precursor-specific differences are a result of slight differences between the two-product yields for these species in Base (Carlton et al., 2010) and BaseM. The comparison between Base and BaseM suggests that while the newer data might not dramatically affect the SOA concentrations in high- $\mathrm{NO}_{x}$ (or urban) areas - at least those that still have marginal biogenic contributions - the newer data could increase SOA concentrations (factor of $\sim 2$ ) in low$\mathrm{NO}_{x}$ (or rural/remote) areas. One important difference is that the BaseM parameterizations for mono- and sesquiterpenes indicate a $\mathrm{NO}_{x}$ dependence, whereas the Base parameterizations have no $\mathrm{NO}_{x}$ dependence for these compounds. This has implications for the assessment of anthropogenic influences on biogenic SOA and whether biogenic SOA can, to some extent, be controlled (Carlton et al., 2007). Further, the substantial decrease in alkane SOA concentrations in BaseM compared to Base suggests that the Base alkane parameterization might be over-predicting SOA formation from alka-

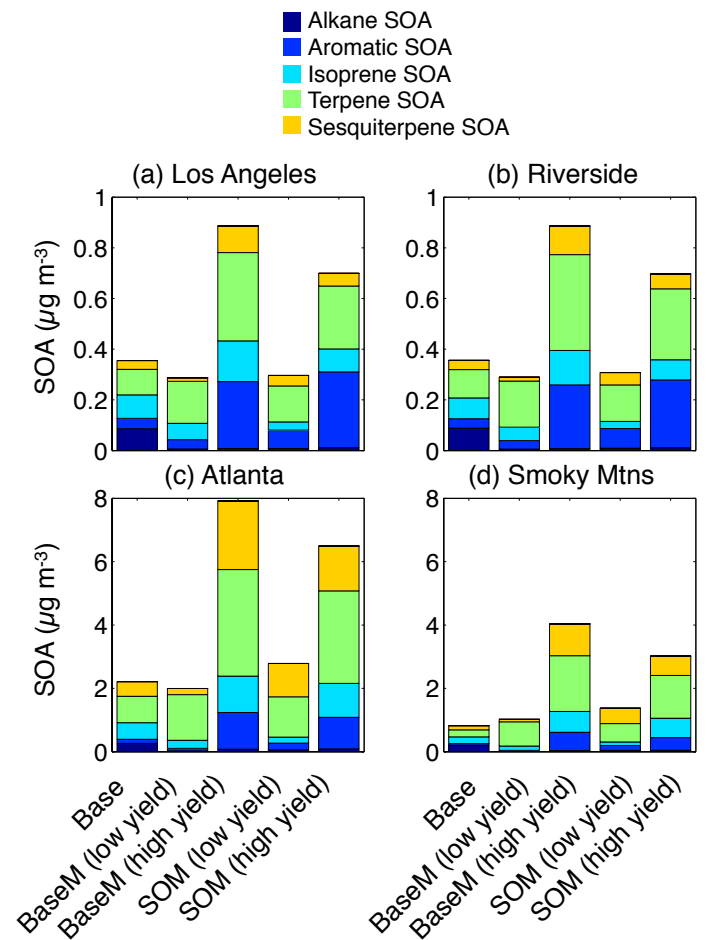

Figure 1. 14-day averaged SOA concentrations at Los Angeles (a), Riverside (b), Atlanta (c) and Smoky Mountains (d) for the Base, BaseM, and SOM simulations resolved by the precursor/pathway.

nes, at least those that make up ALK5, making it an even smaller fraction of the total SOA mass.

\subsection{Effect of constrained multi-generational oxidation}

\subsubsection{SOA concentrations}

Predictions from BaseM and SOM, which were parameterized using the same data, were used to investigate the influence of multi-generational oxidation. Domain-wide, 14day averaged SOA concentrations from BaseM and SOM for the SoCAB and for the eastern US, along with the ratio of the SOA concentrations between SOM and BaseM, are 

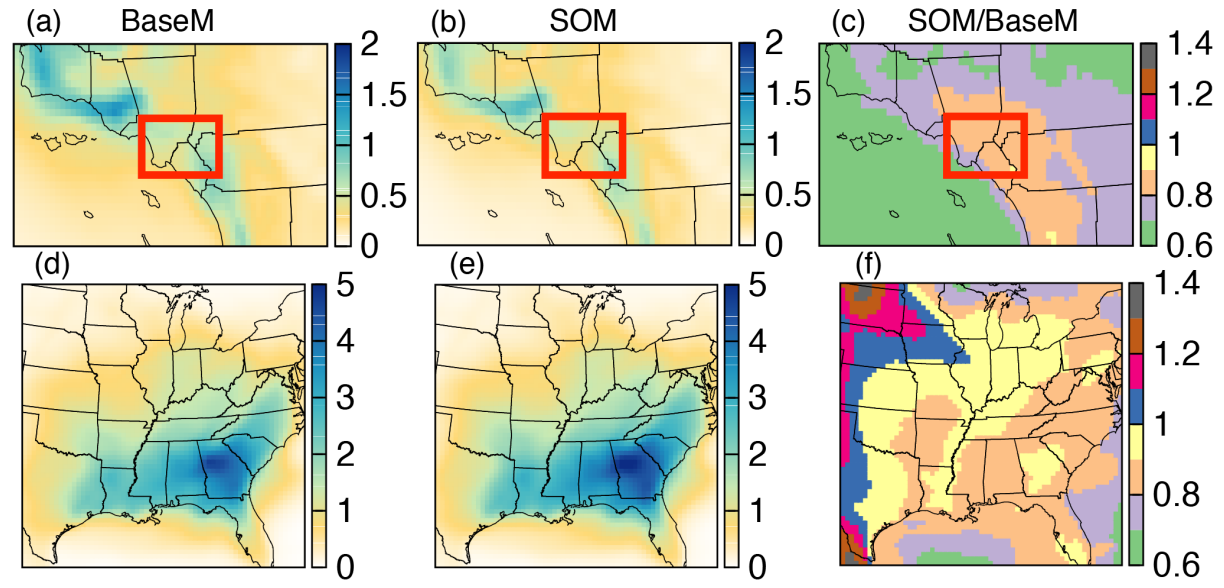

Figure 2. (a, b) 14-day averaged SOA concentrations in SoCAB for the BaseM and SOM simulations. (c) Ratio of the 14-day averaged SOA concentration from the SOM simulation to that from the BaseM simulation. The BaseM and SOM results are averages of the low-yield and high-yield simulations. Red box indicates urban areas surrounding Los Angeles.

shown in Fig. 2. The SOA concentrations presented are averages of the low-yield and high-yield simulations. Consideration of either the low-yield or high-yield simulations individually affects the details, but not the general conclusions about multi-generational oxidation below, even though the SOA mass concentrations from the high-yield simulations are typically $2-4$ times larger than from the low-yield simulations (see Fig. S2). In both the SoCAB and the eastern USA, the predicted spatial distribution of SOA is generally similar between BaseM and SOM, with only minor differences evident in some locations. For the SoCAB, the SOA concentrations in SOM are somewhat lower everywhere compared to BaseM, by 10-20\% in the Los Angeles metropolitan area (marked by a red box) and by about 20-30\% in regions dominated by biogenic SOA (e.g., Los Padres National Forest located in the northwest corner of the simulated domain). Similarly, the SOM predictions for SOA concentrations in the eastern USA are 0-20\% lower than BaseM predictions over most of the domain. The urban vs. biogenic difference was not evident, probably owing to a coarser grid resolution ( $36 \mathrm{~km}$ for the eastern USA vs. $8 \mathrm{~km}$ for the SoCAB). It appears that multi-generational oxidation does not dramatically increase (from additional functionalization reactions) or decrease (from additional fragmentation reactions) the total SOA concentrations formed from the precursor compounds considered in either region.

In Fig. 1, at all sites, the SOM SOA concentrations are roughly the same or slightly higher than the BaseM SOA concentrations for the low-yield simulations but consistently lower for the high-yield simulations, by $18-25 \%$. When averaged, the SOM SOA concentrations are slightly lower than the BaseM simulations, largely due to the lower predictions of SOA from mono-terpene and sesquiterpenes in the SOM high-yield simulations. The low- vs. high-yield distinction suggests that the SOM-predicted SOA is probably similar to BaseM-predicted SOA in urban areas (low yield or high $\mathrm{NO}_{x}$ ) but lower in rural/remote areas (high yield or low $\mathrm{NO}_{x}$ ).

The seemingly limited influence of multi-generational oxidation on total SOA concentrations runs counter to the findings from previous work that suggests multi-generational oxidation is an important source of SOA (Robinson et al., 2007; Murphy and Pandis, 2009; Baek et al., 2011; Fast et al., 2014; Dzepina et al., 2009). However, these previous efforts accounted for multi-generational VOC oxidation by adding ageing reactions for semi-volatile products on top of an existing parameterization, similar to the COM model, and thus may suffer from double counting to some extent (we will return to this point later). These results also indicate that the two-product model parameterization inherently captures some of the influence of multi-generational oxidation, at least over the timescales and conditions relevant for the SoCAB and the eastern USA. This can be understood by considering that, although the two-product model assumes non-reactive products, the chamber-observed SOA formation is dependent on production from all reaction generations, even at short oxidation lifetimes (half to a full day of photochemistry); the extent to which multi-generational oxidation influences the two-product fit parameters will depend on the extent to which later generation products are responsible for the actual SOA formation in a given experiment. In summary, it is possible that the chamber-observed SOA formation accounts for the majority of the multi-generational oxidation reactions that contribute to SOA mass, and hence a two-product approach to model SOA formation would already include the massenhancement associated with multi-generational oxidation. However, such a two-product model may not necessarily accurately represent the chemical composition of SOA.

The behavior of SOM vs. BaseM predictions is similar in the SoCAB and the eastern USA, with minor differ- 
Table 2. Fractional bias and fractional error at STN and IMPROVE sites for the SoCAB and the eastern USA for the Base, BaseM (average of low- and high-yield), COM and SOM (average of low- and high-yield) simulations. Bold, italics, and bold-italics represent good, average and poor model performance (Boylan and Russell, 2006).

\begin{tabular}{|c|c|c|c|c|c|c|c|c|}
\hline \multirow[t]{3}{*}{ Simulation } & \multicolumn{4}{|c|}{ SoCAB } & \multicolumn{4}{|c|}{ Eastern USA } \\
\hline & \multicolumn{2}{|c|}{ STN } & \multicolumn{2}{|c|}{ IMPROVE } & \multicolumn{2}{|c|}{ STN } & \multicolumn{2}{|c|}{ IMPROVE } \\
\hline & $\begin{array}{r}\text { Frac. } \\
\text { bias }\end{array}$ & $\begin{array}{l}\text { Frac. } \\
\text { error }\end{array}$ & $\begin{array}{r}\text { Frac. } \\
\text { bias }\end{array}$ & $\begin{array}{l}\text { Frac. } \\
\text { error }\end{array}$ & $\begin{array}{r}\text { Frac. } \\
\text { bias }\end{array}$ & $\begin{array}{l}\text { Frac. } \\
\text { error }\end{array}$ & $\begin{array}{c}\text { Frac. } \\
\text { bias }\end{array}$ & $\begin{array}{l}\text { Frac. } \\
\text { error }\end{array}$ \\
\hline Base & -62 & 62 & -34 & 43 & -78 & 89 & -10 & 57 \\
\hline BaseM & -61 & 62 & -30 & 41 & -78 & 87 & -8 & 57 \\
\hline SOM & -62 & 63 & -33 & 43 & -80 & 89 & -12 & 55 \\
\hline $\mathrm{COM}$ & -28 & 43 & 27 & 50 & 3 & 61 & 85 & 92 \\
\hline
\end{tabular}

ences likely related to the size of the domain and the average atmospheric lifetime of the simulated SOA, differences in the evolution of SOA from the various precursors, and the dominance of certain precursors in different domains. These precursor-specific SOA concentrations are visualized in Fig. 1 and listed as domain-wide averages in Table S4. These results indicate that SOM typically produced more SOA from alkanes (although very little overall) but less from terpenes and isoprene in both the SoCAB and the eastern USA, compared to BaseM. For aromatics and sesquiterpenes the concentrations are generally similar between the two models, although slightly greater for sesquiterpenes for the eastern USA SOM simulations. The use of the SOM model that inherently accounts for multi-generational oxidation leads to more SOA mass for some compounds (due to enhanced functionalization) but less SOA mass for others (due to fragmentation) compared to a static representation of the semi-volatile products. SOA concentrations in chamber photooxidation experiments have been observed to decrease at longer times for some VOCs, notably isoprene (Chhabra et al., 2011) and $\alpha$-pinene (Henry and Donahue, 2012). Such behavior is captured by SOM but not by BaseM, which does not account for fragmentation. Consequently, SOA concentrations in BaseM can never decrease from reactions. The general similarity in the total simulated SOA from BaseM and SOM results in large part from offsetting trends associated with different SOA precursors. This suggests that the use of constrained multi-generational oxidation SOA models, such as SOM, over two-product models may help to provide a clearer picture of the sources of SOA in a given region, even if the different modeling approaches lead to similar total SOA mass concentrations.

The simulated total OA concentrations (POA + SOA) are compared to ambient OA measurements made at the STN (Speciated Trends Network) and IMPROVE (Interagency Monitoring of Protected Visual Environments) air quality monitoring sites in the SoCAB and the eastern USA. (IMPROVE sites tend to be remote and with lower OA concentrations compared to STN sites, which tend to be more urban.) Table 2 lists statistical metrics of fractional bias and fractional error that capture model performance for OA for all simulations for both domains at the STN and IMPROVE sites. The simulated SOA fraction of total OA differs greatly between the SoCAB $(\sim 10 \%)$ and the eastern USA $(\sim 80 \%)$. Consequently, changes in the amount of SOA simulated will have a larger influence on the total OA in the eastern USA, and thus on the comparison with observations. Despite these differences, there is no substantial change in model performance between Base, BaseM and SOM in either domain, with all simulations under-predicting the total OA. In contrast, COM, which leads to substantial increases in the simulated SOA mass concentrations within both domains (see Sect. 3.3), improved model performance at the STN and IMPROVE sites for the SoCAB and at the STN sites for the eastern USA.

\subsubsection{SOA volatility}

The effective volatility of the SOA was characterized for the Base, BaseM and SOM simulations. SOA volatility influences the sensitivity of the SOA to dilution and temperature changes. Since Base, BaseM and SOM use model species that have very different volatilities, as characterized by the species saturation concentration, $C^{*}$, volatility distributions were developed in which individual species are grouped into logarithmically spaced bins of effective $C^{*}$, referred to as volatility basis set-equivalent $\left(\mathrm{VBS}_{\mathrm{eq}}\right)$ distributions (Donahue et al., 2006). In Fig. 3a and c, we show the normalized, episode-averaged $\mathrm{VBS}_{\mathrm{eq}}$ distributions of SOA at Los Angeles and Atlanta for the Base, BaseM and SOM simulations. Qualitatively, the SOA $\mathrm{VBS}_{\mathrm{eq}}$ distributions for Base and BaseM are similar, with the bulk of the gas + particle mass being in the $C^{*}=1$ to $1000 \mu \mathrm{g} \mathrm{m}^{-3}$ range. In sharp contrast, the SOA volatility distribution for the SOM simulation had a substantial fraction of SOA mass in the $C^{*}=0.0001$ to $1 \mu \mathrm{g} \mathrm{m}^{-3}$ range, much lower than the Base/BaseM simulations. At atmospherically relevant OA concentrations (1$10 \mu \mathrm{g} \mathrm{m}^{-3}$ ), the mass in these low $C^{*}$ bins would be exclusively in the particle-phase. 

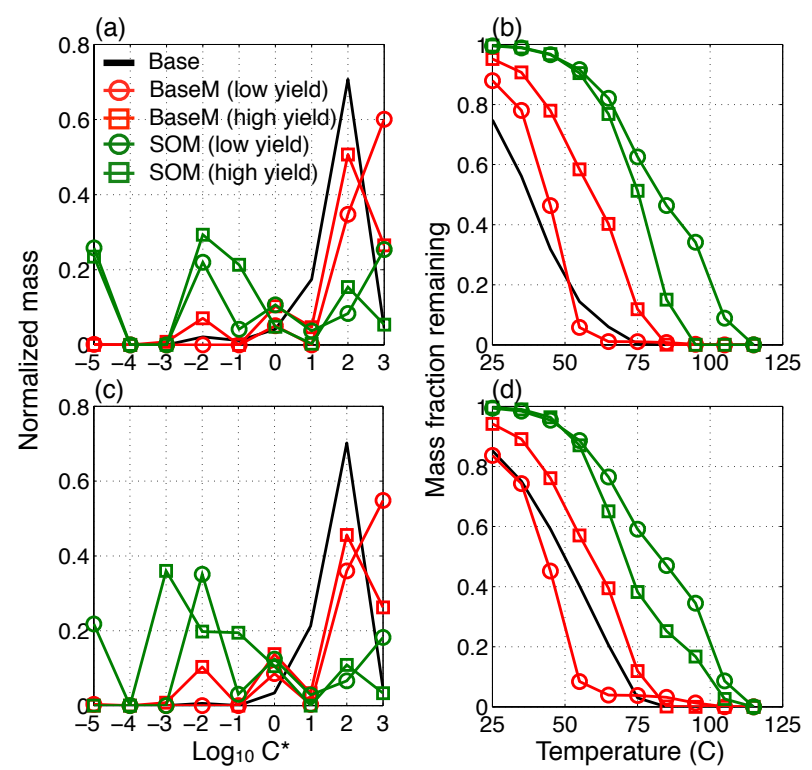

Figure 3. Volatility distributions of the 14-day averaged gas + particle SOA mass at Los Angeles (a) and Atlanta (c) for the Base, BaseM and SOM simulations. Thermograms that capture the volatility of the 14-day averaged gas + particle SOA mass at Los Angeles (b) and Atlanta (d) for the Base, BaseM and SOM simulations.

It is not possible to compare the simulated volatility distributions to ambient observations since direct measurement of volatility distributions has not been demonstrated for such low $C^{*}$ species. However, the effective volatility of SOA particles has been experimentally assessed by considering the response of particles to heating in a thermodenuder (Cappa and Jimenez, 2010; Huffman et al., 2009). High volatility species generally evaporate at lower temperatures than lowvolatility species. The theoretical response of the predicted SOA mass, expressed as the mass fraction remaining (MFR), to heating in a thermodenuder over the range 25 to $105^{\circ} \mathrm{C}$ was simulated using the model of Cappa (2010). The $C^{*}$ values varied with temperature according to the ClausiusClapeyron equation and the enthalpy of vaporization was assumed to be a function of $C^{*}$ with $\Delta H_{\mathrm{vap}}=131-11 \times$ $\log _{10} C^{*}$ (see Supplement section Thermodenuder Model). We plot the results in Fig. $3 b$ and d. At both Los Angeles and Atlanta, differences in the predicted SOA volatility are quite evident. In general, the effective SOA volatility was higher in the Base and BaseM simulations than in the SOM simulations. The SOA from the Base and BaseM simulations is almost entirely evaporated when heated to $70^{\circ} \mathrm{C}$, and some evaporation occurs even at $25^{\circ} \mathrm{C}$ as a response to vapor stripping in the denuder. In contrast, the SOA from the SOM simulations did not entirely evaporate until $100^{\circ} \mathrm{C}$ and exhibits a more gradual decrease with temperature. The SOMsimulated SOA TD evaporation is much more similar to the behavior observed in both laboratory experiments and field assessments of SOA volatility (Cappa and Jimenez, 2010; Huffman et al., 2009; Lee et al., 2010). This suggests that SOM is producing SOA with more physically realistic properties even though the Base/BaseM and SOM simulations produced similar SOA concentrations.

\subsubsection{Influence of oligomerization}

The Base-OLIG model includes an oligomerization pathway in which semi-volatile, condensed-phase material is converted to a non-volatile, yet absorptive material on a fixed timescale. This effectively pumps semi-volatile vapors to the particle phase and leads to increased SOA concentrations. It has the additional effect of making the SOA less sensitive to dilution and changes in temperature. To examine the influence of oligomerization, Fig. 4 shows predictions of the precursor-resolved SOA concentrations from the Base, Base-OLIG, SOM and SOM-OLIG simulations for Los Angeles and Riverside, CA. The total SOA concentrations in Base-OLIG are $\sim 60 \%$ higher than Base but the SOA concentrations in SOM-OLIG were only $\sim 14 \%$ higher than SOM. This difference can be understood through the differences between the SOM and Base volatility distributions for semi-volatile species. For the Base model, a large fraction of the oxidation products have $C^{*}>1 \mu \mathrm{g} \mathrm{m}^{-3}$, and thus a sizable fraction is in the gas-phase. This gas-phase material can be viewed as potential SOA, and as oligomers are formed this material is converted to actual SOA. For SOM, much of the material has $C^{*} \leq 1 \mu \mathrm{g} \mathrm{m}^{-3}$, and thus most of it is already in the particle phase. Consequently, when it is converted to oligomers only a marginal influence on the total SOA concentration results. Overall, it is evident that the influence of oligomerization on simulated SOA concentrations is tightly linked to the semi-volatile product distribution. This may influence the timescales of SOA formation, since in SOM production of lower volatility material is related to the timescales of gas-phase oxidation, whereas in Base, the specified oligomerization rate coefficient, which is largely under-constrained, controls the timescale of low (essentially non-) volatile material.

\subsection{Comparing constrained multi-generational oxidation to unconstrained schemes}

The 14-day averaged SOA concentrations from the COM, Base and SOM simulations for the SoCAB and the eastern USA are compared in Fig. 5. Recall that COM allows for conversion of the semi-volatile products in the Base model to lower-volatility products on top of the original 2-product parameterization. The COM simulations predict a factor of 4 to 8 increase in SOA concentrations over the Base and SOM simulations, attributable to the production of low-volatility and non-volatile SOA from the added oxidation reactions. Because COM, like many ad hoc ageing schemes (Simon and Bhave, 2011; Robinson et al., 2007; Pye and Seinfeld, 2010; 
(a) Base

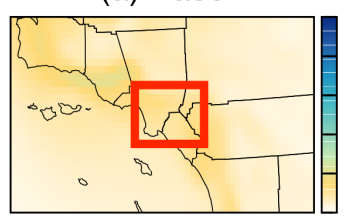

(d) Base

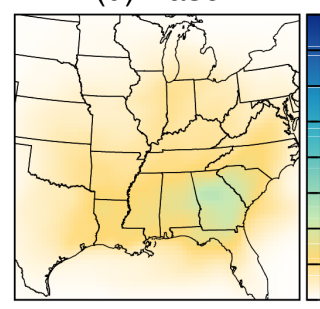

(b) $\mathrm{COM}$

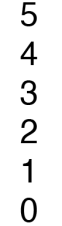

16

14

12

10

8

6

4

2

(e) COM
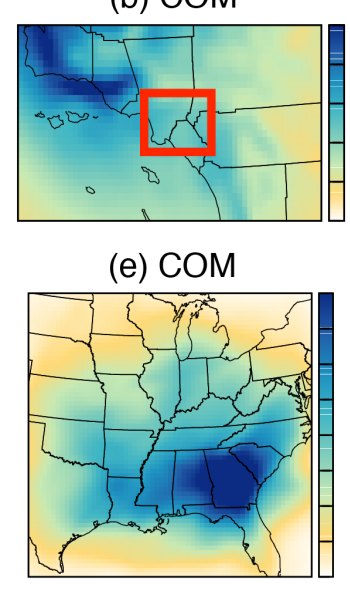

(c) SOM

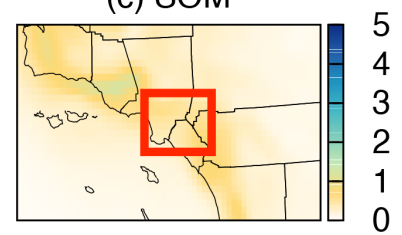

(f) SOM

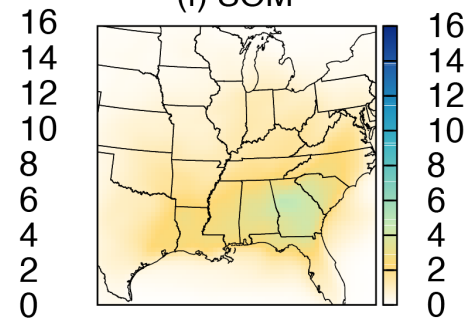

Figure 4. 14-day averaged SOA concentrations at (a) Los Angeles and (b) Riverside for the Base, Base-OLIG, SOM, SOM-OLIG simulations resolved by the precursor/pathway.

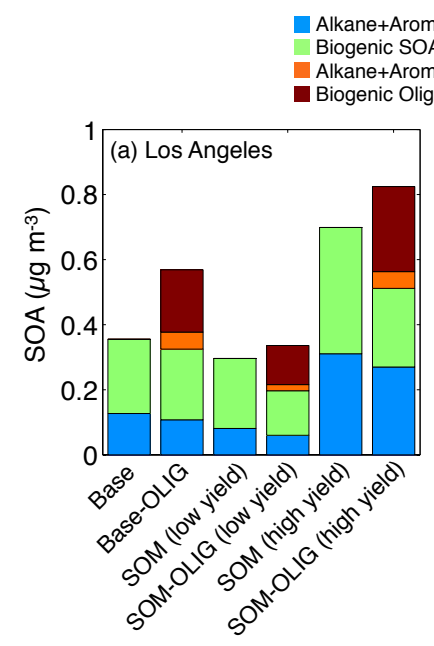

Alkane+Aromatic SOA $\mid$ semi-volatile
Biogenic SOA

Alkane+Aromatic Oligomers $\mid$ non-volatile

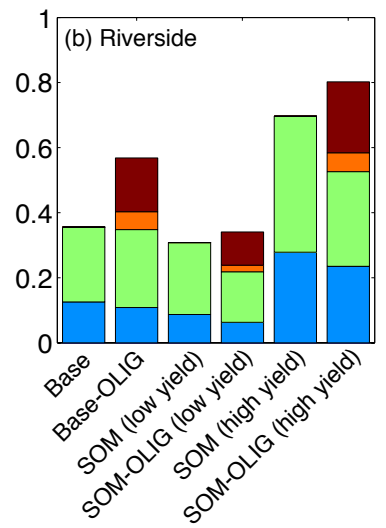

Figure 5. 14-day averaged SOA concentrations in SoCAB (a-c) and the eastern USA (d-f) for the Base, COM and SOM simulations. The SOM results are averages of the low-yield and high-yield simulations.

Baek et al., 2011), lacks fragmentation and adds ageing reactions on top of an existing parameterization, and with sufficient oxidation all semi-volatile products will be converted into non-volatile SOA. This means that the ultimate SOA mass yield is equal to the sum of the mass yields of the individual products, independent of their vapor pressures. Given that SOM inherently accounts for multi-generational oxidation as part of the model parameterization, this comparison clearly suggests that the unconstrained schemes used in the COM simulations form too much SOA and that such schemes are not truly representative of multi-generational oxidation in the atmosphere.

Some previous studies have defended the use of a COMtype model because its implementation improved model per- formance (Lane et al., 2008; Murphy and Pandis, 2009; Shrivastava et al., 2008), as was also observed here (Table 2). However, given that COM-type models remain generally unconstrained and have been inconsistently applied to different VOC precursor types (e.g., ageing of anthropogenics but not biogenics) (Farina et al., 2010; Lane et al., 2008; Murphy and Pandis, 2009), and since recent testing of a COM-type scheme in the laboratory demonstrated that such schemes do, indeed, lead to the over-prediction of SOA mass concentration (Zhao et al., 2015), we suggest that this apparently improved agreement is more likely fortuitous than a true indication of improved representation of atmospheric chemistry. It should be noted that the current study specifically assesses the performance of a COM-type model on the SOA production from traditional VOCs only, exclusive of potential contributions of IVOCs and semi-volatile POA vapors to the SOA burden. Previous studies that have examined the influence of multi-generational oxidation of traditional VOCs using COM-type models have typically combined the effects of VOC ageing and IVOC and POA vapor oxidation (e.g., Murphy and Pandis, 2009; Jathar et al., 2011) together and have not investigated the role of each process separately. Consequently, our results, which isolate the influence of using a COM-type oxidation scheme, suggest COM-type models may be inappropriate for use in regional air quality models even though they can lead to improved model-measurement comparison (Table 2). They also imply that models that employed COM-like schemes have potentially underplayed the role of other important OA formation pathways such as aqueous (aerosol, fog, cloud) processing of water-soluble organics (Ervens et al., 2011) and particle-surface reactions (Liggio et al., 2005; Shiraiwa et al., 2013). Future work to integrate semi-volatile POA treatments with constrained multigenerational ageing schemes like SOM is needed. 


\section{Discussion}

When constrained using the same chamber data, the BaseM (traditional two-product model that does not resolve multigenerational oxidation) and SOM models predict roughly the same SOA mass concentrations and spatial distribution for regional air pollution episodes in the SoCAB and the eastern USA. This suggests that the chamber data used to constrain the BaseM and SOM parameterizations presumably already includes a majority of the SOA mass that would be attributable to multi-generational oxidation. The extent to which multi-generational oxidation influences the production of SOA in a given chamber experiment depends on both the volatility and reactivity of the first-generation products and the timescale of the experiment (Wilson et al., 2012). If SOA formation is dominated by first-generation products, then explicit accounting for multi-generational ageing will not be important. Alternatively, if most SOA is formed from second-generation products with little direct contribution from first-generation products, then a static representation (such as with the 2-product model) might be sufficient even when multi-generational ageing is, in fact, dominant. But if SOA formation is balanced between contributions from first, second and later generation products, then the extent to which a static representation will capture the influence of multi-generational ageing may be highly variable and sensitive to the experimental conditions and number of oxidation lifetimes. Consequently, the appropriateness of extrapolating static model parameterizations to longer (global atmospheric) timescales remains unclear. The results presented here indicate that the 2-product model does capture the influence of multi-generational ageing as part of the parameterization in terms of mass concentration, at least for the regional episodes considered, but it is also apparent that the simulated SOA properties (e.g., volatility) and the explicit contributions of various SOA types are not fully captured by such simple models.

The BaseM and SOM simulations show that the SOA concentrations in the SoCAB and eastern USA vary by a factor of 2 when using parameterizations developed from low vs. high $\mathrm{NO}_{x}$ chamber experiments. Hence, we can argue that for the present simulations $\mathrm{NO}_{x}$ dependence is a much more important factor for SOA production than multi-generational oxidation. While most 3-D models include schemes to simulate the $\mathrm{NO}_{x}$ dependence of SOA formation, these schemes remain ad hoc as they are based on limited experimental measurements and also rely on the ability of the model to accurately predict radical concentrations $\left(\mathrm{RO}_{2}, \mathrm{HO}_{2}\right)$ or VOC-to$\mathrm{NO}_{x}$ ratios. In this work, the model predictions from the lowand high-yield simulations bound the $\mathrm{NO}_{x}$-dependent uncertainty in SOA concentrations and we recommend that future work examine this issue in much more detail.

SOM predicts a modestly different composition of SOA than BaseM despite similar total mass concentrations of SOA. The composition predicted by SOM has a slightly higher contribution from alkanes, aromatics (anthropogenic) and sesquiterpenes and a lower contribution from isoprene and monoterpenes. These modest differences in the predicted composition of SOA have implications for understanding the sources of ambient aerosol and eventually the regulation of these sources to achieve compliance with National Ambient Air Quality Standards (NAAQS). These more accurate SOA predictions resolved by chemical families should be tested in epidemiological studies to determine if they are associated with adverse health effects. Additionally, SOM predicted a much lower-volatility SOA than BaseM, and SOM predictions are in better qualitative agreement with ambient thermodenuder measurements of OA volatility. Since the SOA has a much lower volatility, there is very little enhancement $(10-15 \%)$ with the inclusion of oligomerization reactions, implying that while oligomerization might affect composition, it may not be a source of additional SOA formation as the Base model suggests.

In this work, we consider POA as non-volatile and nonreactive and do not consider SOA contributions from IVOCs or semi-volatile POA vapors. Oxidation of IVOCs and semivolatile POA vapors (i.e., SVOCs) can lead to the production of new SOA mass, but evaporation of POA leads to a decrease in the total OA mass. To some extent, these effects are offsetting (especially for SVOCs, which do not contribute new carbon mass to a model). To the extent that the loss of POA is balanced exactly by the formation of SOA from IVOCs and recycling of semi-volatile POA vapors, the simulations here represent a scenario in which the total OA mass is conserved, although possibly with the wrong spatial distribution (Robinson et al., 2007). Most efforts to incorporate SOA formation from IVOCs and SVOCs have simulated their oxidation using a version of the VBS model in which multi-generational ageing is implicit, but highly underconstrained and structured in such a way that the ultimate (long time) SOA yield is greater than unity because all mass is converted to low-volatility products and oxygen addition is assumed. The SOM framework provides a way to explicitly account for the influence of multi-generational chemistry in SOA formation experiments that include semi-volatile POA vapors and IVOCs (Gordon et al., 2014a, b, 2013; Grieshop et al., 2009a, b; Hennigan et al., 2011; Miracolo et al., 2011, 2012; Platt et al., 2013, 2014; Nordin et al., 2013; Chirico et al., 2010; Heringa et al., 2011; Tkacik et al., 2014), and thus should be useful for constraining the contribution of these compound classes to the ambient OA budget. In addition, the simulations here do not consider the influence of vapor wall losses on SOA formation. Such losses can influence SOA yields in chambers, and consequently the parameterizations that result from fitting of such chamber data. The influence of vapor wall losses on simulated ambient SOA and OA concentrations within the SOM framework is examined in a companion paper (Cappa et al., 2015). Ultimately, models like the SOM can be applied to chamber experiments to 
better understand the role and contribution of POA, IVOCs and vapor wall-losses to total OA.

Finally, the comparison between the constrained SOM and the unconstrained COM (commonly used in large-scale models) suggests that COM may be double counting SOA formation. These simple ageing schemes should be refit to chamber data where all parameters can be matched to observed trends in a self-consistent manner.

\section{The Supplement related to this article is available online at doi:10.5194/acp-16-2309-2016-supplement.}

Acknowledgements. This work was supported by the California Air Resources Board (CARB) under contracts 11-755 and 12-312. Although this work was funded by the CARB, the statements and conclusions are those of the authors and not necessarily those of the CARB.

Edited by: M. Shiraiwa

\section{References}

Ahmadov, R., McKeen, S. A., Robinson, A. L., Bahreini, R., Middlebrook, A. M., de Gouw, J. A., Meagher, J., Hsie, E. Y., Edgerton, E., Shaw, S., and Trainer, M.: A volatility basis set model for summertime secondary organic aerosols over the eastern United States in 2006, J. Geophys. Res.-Atmos., 117, D06301, doi:10.1029/2011JD016831, 2012.

Baek, J., Hu, Y., Odman, M. T., and Russell, A. G.: Modeling secondary organic aerosol in CMAQ using multigenerational oxidation of semi-volatile organic compounds, J. Geophys. Res.Atmos., 116, D22204, doi:10.1029/2011JD015911, 2011.

Bernstein, J. A., Alexis, N., Barnes, C., Bernstein, I. L., Bernstein, J. A., Nel, A., Peden, D., Diaz-Sanchez, D., Tarlo, S. M., and Williams, P. B.: Health effects of air pollution, J. Allergy Clin. Immun., 114, 1116-1123, 2004.

Boylan, J. W. and Russell, A. G.: PM and light extinction model performance metrics, goals, and criteria for three-dimensional air quality models, Atmos. Environ., 40, 4946-4959, 2006.

Cappa, C. D.: A model of aerosol evaporation kinetics in a thermodenuder, Atmos. Meas. Tech., 3, 579-592, doi:10.5194/amt3-579-2010, 2010.

Cappa, C. D. and Jimenez, J. L.: Quantitative estimates of the volatility of ambient organic aerosol, Atmos. Chem. Phys., 10, 5409-5424, doi:10.5194/acp-10-5409-2010, 2010.

Cappa, C. D. and Wilson, K. R.: Multi-generation gas-phase oxidation, equilibrium partitioning, and the formation and evolution of secondary organic aerosol, Atmos. Chem. Phys., 12, 9505-9528, doi:10.5194/acp-12-9505-2012, 2012.

Cappa, C. D., Zhang, X., Loza, C. L., Craven, J. S., Yee, L. D., and Seinfeld, J. H.: Application of the Statistical Oxidation Model (SOM) to Secondary Organic Aerosol formation from photooxidation of $\mathrm{C}_{12}$ alkanes, Atmos. Chem. Phys., 13, 1591-1606, doi:10.5194/acp-13-1591-2013, 2013.
Cappa, C. D., Jathar, S. H., Kleeman, M. J., Docherty, K. S., Jimenez, J. L., Seinfeld, J. H., and Wexler, A. S.: Simulating secondary organic aerosol in a regional air quality model using the statistical oxidation model - Part 2: Assessing the influence of vapor wall losses, Atmos. Chem. Phys. Discuss., 15, 3008130126, doi:10.5194/acpd-15-30081-2015, 2015.

Carlton, A. G., Pinder, R. W., Bhave, P. V., and Pouliot, G. A.: To what extent can biogenic SOA be controlled?, Environ. Sci. Technol., 44, 3376-3380, 2007.

Carlton, A. G., Bhave, P. V., Napelenok, S. L., Edney, E. O., Sarwar, G., Pinder, R. W., Pouliot, G. A., and Houyoux, M.: Model representation of secondary organic aerosol in CMAQv4.7, Environ. Sci. Technol., 44, 8553-8560, 2010.

Carter, W. P. and Heo, G.: Development of revised SAPRC aromatics mechanisms, Atmos. Environ., 77, 404-414, 2013.

Chacon-Madrid, H. J. and Donahue, N. M.: Fragmentation vs. functionalization: chemical aging and organic aerosol formation, Atmos. Chem. Phys., 11, 10553-10563, doi:10.5194/acp11-10553-2011, 2011.

Chacon-Madrid, H. J., Presto, A. A., and Donahue, N. M.: Functionalization vs. fragmentation: n-aldehyde oxidation mechanisms and secondary organic aerosol formation, Phys. Chem. Chem. Phys., 12, 13975-13982, doi:10.1039/c0cp00200c, 2010.

Chacon-Madrid, H. J., Henry, K. M., and Donahue, N. M.: Photooxidation of pinonaldehyde at low $\mathrm{NO}_{x}$ : from chemistry to organic aerosol formation, Atmos. Chem. Phys., 13, 3227-3236, doi:10.5194/acp-13-3227-2013, 2013.

Chen, J., Mao, H., Talbot, R. W., and Griffin, R. J.: Application of the CACM and MPMPO modules using the CMAQ model for the eastern United States, J. Geophys. Res.-Atmos. (1984-2012), 111, D23S25, doi:10.1029/2006JD007603, 2006.

Chhabra, P. S., Ng, N. L., Canagaratna, M. R., Corrigan, A. L., Russell, L. M., Worsnop, D. R., Flagan, R. C., and Seinfeld, J. H.: Elemental composition and oxidation of chamber organic aerosol, Atmos. Chem. Phys., 11, 8827-8845, doi:10.5194/acp-11-88272011, 2011.

Chirico, R., DeCarlo, P. F., Heringa, M. F., Tritscher, T., Richter, R., Prévôt, A. S. H., Dommen, J., Weingartner, E., Wehrle, G., Gysel, M., Laborde, M., and Baltensperger, U.: Impact of aftertreatment devices on primary emissions and secondary organic aerosol formation potential from in-use diesel vehicles: results from smog chamber experiments, Atmos. Chem. Phys., 10, 11545-11563, doi:10.5194/acp-10-11545-2010, 2010.

Donahue, N., Robinson, A., Stanier, C., and Pandis, S.: Coupled partitioning, dilution, and chemical aging of semivolatile organics, Environ. Sci. Technol, 40, 2635-2643, doi:10.1021/es052297c, 2006.

Donahue, N. M., Henry, K. M., Mentel, T. F., Kiendler-Scharr, A., Spindler, C., Bohn, B., Brauers, T., Dorn, H. P., Fuchs, H., and Tillmann, R.: Aging of biogenic secondary organic aerosol via gas-phase OH radical reactions, P. Natl. Acad. Sci., 109, $13503-$ 13508, 2012.

Dzepina, K., Volkamer, R. M., Madronich, S., Tulet, P., Ulbrich, I. M., Zhang, Q., Cappa, C. D., Ziemann, P. J., and Jimenez, J. L.: Evaluation of recently-proposed secondary organic aerosol models for a case study in Mexico City, Atmos. Chem. Phys., 9, 5681-5709, doi:10.5194/acp-9-5681-2009, 2009.

Emmons, L. K., Walters, S., Hess, P. G., Lamarque, J.-F., Pfister, G. G., Fillmore, D., Granier, C., Guenther, A., Kinnison, D., 
Laepple, T., Orlando, J., Tie, X., Tyndall, G., Wiedinmyer, C., Baughcum, S. L., and Kloster, S.: Description and evaluation of the Model for Ozone and Related chemical Tracers, version 4 (MOZART-4), Geosci. Model Dev., 3, 43-67, doi:10.5194/gmd3-43-2010, 2010.

Epstein, S. A., Riipinen, I., and Donahue, N. M.: A semiempirical correlation between enthalpy of vaporization and saturation concentration for organic aerosol, Environ. Sci. Technol., 44, 743748, doi:10.1021/es902497z, 2009.

Ervens, B., Turpin, B. J., and Weber, R. J.: Secondary organic aerosol formation in cloud droplets and aqueous particles (aqSOA): a review of laboratory, field and model studies, Atmos. Chem. Phys., 11, 11069-11102, doi:10.5194/acp-1111069-2011, 2011.

Farina, S. C., Adams, P. J., and Pandis, S. N.: Modeling global secondary organic aerosol formation and processing with the volatility basis set: Implications for anthropogenic secondary organic aerosol, J. Geophys. Res., 115, D09202, doi:10.1029/2009JD013046, 2010.

Fast, J. D., Allan, J., Bahreini, R., Craven, J., Emmons, L., Ferrare, R., Hayes, P. L., Hodzic, A., Holloway, J., Hostetler, C., Jimenez, J. L., Jonsson, H., Liu, S., Liu, Y., Metcalf, A., Middlebrook, A., Nowak, J., Pekour, M., Perring, A., Russell, L., Sedlacek, A., Seinfeld, J., Setyan, A., Shilling, J., Shrivastava, M., Springston, S., Song, C., Subramanian, R., Taylor, J. W., Vinoj, V., Yang, Q., Zaveri, R. A., and Zhang, Q.: Modeling regional aerosol and aerosol precursor variability over California and its sensitivity to emissions and long-range transport during the 2010 CalNex and CARES campaigns, Atmos. Chem. Phys., 14, 10013-10060, doi:10.5194/acp-14-10013-2014, 2014.

Goldstein, A. H. and Galbally, I. E.: Known and unexplored organic constituents in the earth's atmosphere, Environ. Sci. Technol., 41, 1514-1521, doi:10.1021/es072476p, 2007.

Gordon, T. D., Tkacik, D. S., Presto, A. A., Zhang, M., Jathar, S. H., Nguyen, N. T., Massetti, J., Truong, T., Cicero-Fernandez, P., Maddox, C., Rieger, P., Chattopadhyay, S., Maldonado, H., Maricq, M. M., and Robinson, A. L.: Primary Gas- and ParticlePhase Emissions and Secondary Organic Aerosol Production from Gasoline and Diesel Off-Road Engines, Environ. Sci. Technol., 47, 14137-14146, 2013.

Gordon, T. D., Presto, A. A., May, A. A., Nguyen, N. T., Lipsky, E. M., Donahue, N. M., Gutierrez, A., Zhang, M., Maddox, C., Rieger, P., Chattopadhyay, S., Maldonado, H., Maricq, M. M., and Robinson, A. L.: Secondary organic aerosol formation exceeds primary particulate matter emissions for lightduty gasoline vehicles, Atmos. Chem. Phys., 14, 4661-4678, doi:10.5194/acp-14-4661-2014, 2014a.

Gordon, T. D., Presto, A. A., Nguyen, N. T., Robertson, W. H., Na, K., Sahay, K. N., Zhang, M., Maddox, C., Rieger, P., Chattopadhyay, S., Maldonado, H., Maricq, M. M., and Robinson, A. L.: Secondary organic aerosol production from diesel vehicle exhaust: impact of aftertreatment, fuel chemistry and driving cycle, Atmos. Chem. Phys., 14, 4643-4659, doi:10.5194/acp-14-46432014, 2014b.

Grieshop, A. P., Donahue, N. M., and Robinson, A. L.: Laboratory investigation of photochemical oxidation of organic aerosol from wood fires 2: analysis of aerosol mass spectrometer data, Atmos. Chem. Phys., 9, 2227-2240, doi:10.5194/acp-9-2227-2009, 2009a.
Grieshop, A. P., Logue, J. M., Donahue, N. M., and Robinson, A. L.: Laboratory investigation of photochemical oxidation of organic aerosol from wood fires 1: measurement and simulation of organic aerosol evolution, Atmos. Chem. Phys., 9, 1263-1277, doi:10.5194/acp-9-1263-2009, 2009 b.

Guenther, A., Karl, T., Harley, P., Wiedinmyer, C., Palmer, P. I., and Geron, C.: Estimates of global terrestrial isoprene emissions using MEGAN (Model of Emissions of Gases and Aerosols from Nature), Atmos. Chem. Phys., 6, 3181-3210, doi:10.5194/acp-63181-2006, 2006.

Hennigan, C. J., Miracolo, M. A., Engelhart, G. J., May, A. A., Presto, A. A., Lee, T., Sullivan, A. P., McMeeking, G. R., Coe, H., Wold, C. E., Hao, W.-M., Gilman, J. B., Kuster, W. C., de Gouw, J., Schichtel, B. A., Collett Jr., J. L., Kreidenweis, S. M., and Robinson, A. L.: Chemical and physical transformations of organic aerosol from the photo-oxidation of open biomass burning emissions in an environmental chamber, Atmos. Chem. Phys., 11, 7669-7686, doi:10.5194/acp-11-7669-2011, 2011.

Henry, K. M. and Donahue, N. M.: Photochemical aging of $\alpha$ pinene secondary organic aerosol: effects of $\mathrm{OH}$ radical sources and photolysis, J. Phys. Chem. A, 116, 5932-5940, 2012.

Henze, D. K., Seinfeld, J. H., Ng, N. L., Kroll, J. H., Fu, T.-M., Jacob, D. J., and Heald, C. L.: Global modeling of secondary organic aerosol formation from aromatic hydrocarbons: highvs. low-yield pathways, Atmos. Chem. Phys., 8, 2405-2420, doi:10.5194/acp-8-2405-2008, 2008.

Heringa, M. F., DeCarlo, P. F., Chirico, R., Tritscher, T., Dommen, J., Weingartner, E., Richter, R., Wehrle, G., Prévôt, A. S. H., and Baltensperger, U.: Investigations of primary and secondary particulate matter of different wood combustion appliances with a high-resolution time-of-flight aerosol mass spectrometer, Atmos. Chem. Phys., 11, 5945-5957, doi:10.5194/acp-11-59452011, 2011.

Huffman, J., Docherty, K., Mohr, C., Cubison, M., Ulbrich, I., Ziemann, P., Onasch, T., and Jimenez, J.: Chemically-resolved volatility measurements of organic aerosol fom different sources, Environ. Sci. Technol., 43, 5351-5357, 2009.

Pachauri, R. K., Allen, M. R., Barros, V. R., Broome, J., Cramer, W., Christ, R., Church, J. A., Clarke, L., Dahe, Q., Dasgupta, P., Dubash, N. K., Edenhofer, O., Elgizouli, I., Field, C. B., Forster, P., Friedlingstein, P., Fuglestvedt, J., Gomez-Echeverri, L., Hallegatte, S., Hegerl, G., Howden, M., Jiang, K., Jimenez Cisneroz, B., Kattsov, V., Lee, H., Mach, K. J., Marotzke, J., Mastrandrea, M. D., Meyer, L., Minx, J., Mulugetta, Y., O’Brien, K., Oppenheimer, M., Pereira, J. J., Pichs-Madruga, R., Plattner, G. K., Pörtner, H.-O., Power, S. B., Preston, B., Ravindranath, N. H., Reisinger, A., Riahi, K., Rusticucci, M., Scholes, R., Seyboth, K., Sokona, Y., Stavins, R., Stocker, T. F., Tschakert, P., van Vuuren, D., and van Ypserle, J. P.: Climate Change 2014: Synthesis Report. Contribution of Working Groups I, II and III to the Fifth Assessment Report of the Intergovernmental Panel on Climate Change, edited by: Pachauri, R. K., and Meyer, L., IPCC, Geneva, Switzerland, 151 pp., 2014.

Jathar, S. H., Farina, S. C., Robinson, A. L., and Adams, P. J.: The influence of semi-volatile and reactive primary emissions on the abundance and properties of global organic aerosol, Atmos. Chem. Phys., 11, 7727-7746, doi:10.5194/acp-11-77272011, 2011. 
Jathar, S. H., Cappa, C. D., Wexler, A. S., Seinfeld, J. H., and Kleeman, M. J.: Multi-generational oxidation model to simulate secondary organic aerosol in a 3-D air quality model, Geosci. Model Dev., 8, 2553-2567, doi:10.5194/gmd-8-2553-2015, 2015.

Jimenez, J. L., Canagaratna, M. R., Donahue, N. M., Prevot, A. S. H., Zhang, Q., Kroll, J. H., DeCarlo, P. F., Allan, J. D., Coe, H., Ng, N. L., Aiken, A. C., Docherty, K. S., Ulbrich, I. M., Grieshop, A. P., Robinson, A. L., Duplissy, J., Smith, J. D., Wilson, K. R., Lanz, V. A., Hueglin, C., Sun, Y. L., Tian, J., Laaksonen, A., Raatikainen, T., Rautiainen, J., Vaattovaara, P., Ehn, M., Kulmala, M., Tomlinson, J. M., Collins, D. R., Cubison, M. J., E, Dunlea, J., Huffman, J. A., Onasch, T. B., Alfarra, M. R., Williams, P. I., Bower, K., Kondo, Y., Schneider, J., Drewnick, F., Borrmann, S., Weimer, S., Demerjian, K., Salcedo, D., Cottrell, L., Griffin, R., Takami, A., Miyoshi, T., Hatakeyama, S., Shimono, A., Sun, J. Y., Zhang, Y. M., Dzepina, K., Kimmel, J. R., Sueper, D., Jayne, J. T., Herndon, S. C., Trimborn, A. M., Williams, L. R., Wood, E. C., Middlebrook, A. M., Kolb, C. E., Baltensperger, U., and Worsnop, D. R.: Evolution of Organic Aerosols in the Atmosphere, Science, 326, 1525-1529, doi:10.1126/science.1180353, 2009.

Johnson, D., Utembe, S. R., Jenkin, M. E., Derwent, R. G., Hayman, G. D., Alfarra, M. R., Coe, H., and McFiggans, G.: Simulating regional scale secondary organic aerosol formation during the TORCH 2003 campaign in the southern UK, Atmos. Chem. Phys., 6, 403-418, doi:10.5194/acp-6-403-2006, 2006.

Kalberer, M., Paulsen, D., Sax, M., Steinbacher, M., Dommen, J., Prevot, A. S. H., Fisseha, R., Weingartner, E., Frankevich, V., Zenobi, R., and Baltensperger, U.: Identification of polymers as major components of atmospheric organic aerosols, Science, 303, 1659-1662, doi:10.1126/science.1092185, 2004.

Kleeman, M. J. and Cass, G. R.: A 3-D Eulerian source-oriented model for an externally mixed aerosol, Environ. Sci. Technol., 35, 4834-4848, 2001.

Koo, B., Knipping, E., and Yarwood, G.: 1.5-Dimensional volatility basis set approach for modeling organic aerosol in CAMx and CMAQ, Atmos. Environ., 95, 158-164, 2014.

Lambe, A. T., Onasch, T. B., Croasdale, D. R., Wright, J. P., Martin, A. T., Franklin, J. P., Massoli, P., Kroll, J. H., Canagaratna, M. R., and Brune, W. H.: Transitions from functionalization to fragmentation reactions of laboratory secondary organic aerosol (SOA) generated from the $\mathrm{OH}$ oxidation of alkane precursors, Environ. Sci. Technol., 46, 5430-5437, 2012.

Lane, T. E., Donahue, N. M., and Pandis, S. N.: Simulating secondary organic aerosol formation using the volatility basis-set approach in a chemical transport model, Atmos. Environ., 42, 7439-7451, 2008.

Lee, B. H., Kostenidou, E., Hildebrandt, L., Riipinen, I., Engelhart, G. J., Mohr, C., DeCarlo, P. F., Mihalopoulos, N., Prevot, A. S. H., Baltensperger, U., and Pandis, S. N.: Measurement of the ambient organic aerosol volatility distribution: application during the Finokalia Aerosol Measurement Experiment (FAME2008), Atmos. Chem. Phys., 10, 12149-12160, doi:10.5194/acp10-12149-2010, 2010.

Lee-Taylor, J., Madronich, S., Aumont, B., Baker, A., Camredon, M., Hodzic, A., Tyndall, G. S., Apel, E., and Zaveri, R. A.: Explicit modeling of organic chemistry and secondary organic aerosol partitioning for Mexico City and its outflow plume,
Atmos. Chem. Phys., 11, 13219-13241, doi:10.5194/acp-1113219-2011, 2011.

Liggio, J., Li, S. M., and McLaren, R.: Reactive uptake of glyoxal by particulate matter, J. Geophys. Res.-Atmos. (1984-2012), 110, D10304, doi:10.1029/2004JD005113, 2005.

Lin, G., Penner, J. E., Sillman, S., Taraborrelli, D., and Lelieveld, J.: Global modeling of SOA formation from dicarbonyls, epoxides, organic nitrates and peroxides, Atmos. Chem. Phys., 12, 47434774, doi:10.5194/acp-12-4743-2012, 2012.

Loza, C. L., Craven, J. S., Yee, L. D., Coggon, M. M., Schwantes, R. H., Shiraiwa, M., Zhang, X., Schilling, K. A., Ng, N. L., Canagaratna, M. R., Ziemann, P. J., Flagan, R. C., and Seinfeld, J. H.: Secondary organic aerosol yields of 12-carbon alkanes, Atmos. Chem. Phys., 14, 1423-1439, doi:10.5194/acp-14-14232014, 2014.

Matsunaga, A. and Ziemann, P. J.: Gas-wall partitioning of organic compounds in a Teflon film chamber and potential effects on reaction product and aerosol yield measurements, Aerosol Sci. Tech., 44, 881-892, 2010.

McVay, R. C., Cappa, C. D., and Seinfeld, J. H.: Vapor-Wall Deposition in Chambers: Theoretical Considerations, Environ. Sci Technol., 48, 10251-10258, 2014.

Miracolo, M. A., Hennigan, C. J., Ranjan, M., Nguyen, N. T., Gordon, T. D., Lipsky, E. M., Presto, A. A., Donahue, N. M., and Robinson, A. L.: Secondary aerosol formation from photochemical aging of aircraft exhaust in a smog chamber, Atmos. Chem. Phys., 11, 4135-4147, doi:10.5194/acp-11-4135-2011, 2011.

Miracolo, M. A., Drozd, G. T., Jathar, S., Presto, A. A., Lipsky, E., Corporan, E., and Robinson, A.: Fuel composition and secondary organic aerosol formation: gas-turbine exhaust and alternative aviation fuels, Environ. Sci. Technol., 46, 8493-8501, doi:10.1021/es300350c, 2012.

Murphy, B. and Pandis, S.: Simulating the formation of semivolatile primary and secondary organic aerosol in a regional chemical transport model, Environ. Sci. Technol., 43, 4722-4728, doi:10.1021/es803168a, 2009.

Nordin, E. Z., Eriksson, A. C., Roldin, P., Nilsson, P. T., Carlsson, J. E., Kajos, M. K., Hellén, H., Wittbom, C., Rissler, J., Löndahl, J., Swietlicki, E., Svenningsson, B., Bohgard, M., Kulmala, M., Hallquist, M., and Pagels, J. H.: Secondary organic aerosol formation from idling gasoline passenger vehicle emissions investigated in a smog chamber, Atmos. Chem. Phys., 13, 6101-6116, doi:10.5194/acp-13-6101-2013, 2013.

Odum, J. R., Hoffmann, T., Bowman, F., Collins, D., Flagan, R. C., and Seinfeld, J. H.: Gas/particle partitioning and secondary organic aerosol yields, Environ. Sci. Technol., 30, 2580-2585, 1996.

Platt, S. M., El Haddad, I., Zardini, A. A., Clairotte, M., Astorga, C., Wolf, R., Slowik, J. G., Temime-Roussel, B., Marchand, N., Ježek, I., Drinovec, L., Mocnik, G., Möhler, O., Richter, R., Barmet, P., Bianchi, F., Baltensperger, U., and Prévôt, A. S. H.: Secondary organic aerosol formation from gasoline vehicle emissions in a new mobile environmental reaction chamber, Atmos. Chem. Phys., 13, 9141-9158, doi:10.5194/acp-13-91412013, 2013.

Platt, S. M., Haddad, I. E., Pieber, S. M., Huang, R. J., Zardini, A. A., Clairotte, M., Suarez-Bertoa, R., Barmet, P., Pfaffenberger, L., Wolf, R., Slowik, J. G., Fuller, S. J., Kalberer, M., Chirico, R., Dommen, J., Astorga, C., Zimmermann, R., Marc- 
hand, N., Hellebust, S., Temime-Roussel, B., Baltensperger, U., and Prévôt, A. S. H.: Two-stroke scooters are a dominant source of air pollution in many cities, Nature communications, 5, 3749, doi:10.1038/ncomms4749, 2014.

Pye, H. O. T. and Seinfeld, J. H.: A global perspective on aerosol from low-volatility organic compounds, Atmos. Chem. Phys., 10, 4377-4401, doi:10.5194/acp-10-4377-2010, 2010.

Robinson, A. L., Donahue, N. M., Shrivastava, M. K., Weitkamp, E. A., Sage, A. M., Grieshop, A. P., Lane, T. E., Pierce, J. R., and Pandis, S. N.: Rethinking organic aerosols: Semivolatile emissions and photochemical aging, Science, 315, 1259-1262, 2007.

Shiraiwa, M., Yee, L. D., Schilling, K. A., Loza, C. L., Craven, J. S., Zuend, A., Ziemann, P. J., and Seinfeld, J. H.: Size distribution dynamics reveal particle-phase chemistry in organic aerosol formation, P. Natl. Acad. Sci., 110, 11746-11750, 2013.

Shrivastava, M. K., Lane, T. E., Donahue, N. M., Pandis, S. N., and Robinson, A. L.: Effects of gas particle partitioning and aging of primary emissions on urban and regional organic aerosol concentrations, J. Geophys. Res.-Atmos., 113, D18301, doi:10.1029/2007JD009735, 2008.

Simon, H. and Bhave, P. V.: Simulating the degree of oxidation in atmospheric organic particles, Environ. Sci. Technol., 46, 331339, 2011.

Surratt, J. D., Lewandowski, M., Offenberg, J. H., Jaoui, M., Kleindienst, T. E., Edney, E. O., and Seinfeld, J. H.: Effect of acidity on secondary organic aerosol formation from isoprene, Environ. Sci. Technol., 41, 5363-5369, 2007.

Tkacik, D. S., Lambe, A. T., Jathar, S., Li, X., Presto, A. A., Zhao, Y., Blake, D., Meinardi, S., Jayne, J. T., Croteau, P. L., and Robinson, A. L.: Secondary Organic Aerosol Formation from in-Use Motor Vehicle Emissions Using a Potential Aerosol Mass Reactor, Environ. Sci. Technol., 48, 11235-11242, doi:10.1021/es502239v, 2014.

Tsimpidi, A. P., Karydis, V. A., Zavala, M., Lei, W., Molina, L., Ulbrich, I. M., Jimenez, J. L., and Pandis, S. N.: Evaluation of the volatility basis-set approach for the simulation of organic aerosol formation in the Mexico City metropolitan area, Atmos. Chem. Phys., 10, 525-546, doi:10.5194/acp-10-525-2010, 2010.
Utembe, S. R., Cooke, M. C., Archibald, A. T., Shallcross, D. E., Derwent, R. G., and Jenkin, M. E.: Simulating secondary organic aerosol in a 3-D Lagrangian chemistry transport model using the reduced Common Representative Intermediates mechanism (CRI v2-R5), Atmos. Environ., 45, 1604-1614, 2011.

Wiedinmyer, C., Akagi, S. K., Yokelson, R. J., Emmons, L. K., AlSaadi, J. A., Orlando, J. J., and Soja, A. J.: The Fire INventory from NCAR (FINN): a high resolution global model to estimate the emissions from open burning, Geosci. Model Dev., 4, 625641, doi:10.5194/gmd-4-625-2011, 2011.

Wilson, K. R., Smith, J. D., Kessler, S. H., and Kroll, J. H.: The statistical evolution of multiple generations of oxidation products in the photochemical aging of chemically reduced organic aerosol, Phys. Chem. Chem. Phys., 14, 1468-1479, 2012.

Yee, L. D., Kautzman, K. E., Loza, C. L., Schilling, K. A., Coggon, M. M., Chhabra, P. S., Chan, M. N., Chan, A. W. H., Hersey, S. P., Crounse, J. D., Wennberg, P. O., Flagan, R. C., and Seinfeld, J. H.: Secondary organic aerosol formation from biomass burning intermediates: phenol and methoxyphenols, Atmos. Chem. Phys., 13, 8019-8043, doi:10.5194/acp-13-8019-2013, 2013.

Ying, Q. and Li, J.: Implementation and initial application of the near-explicit Master Chemical Mechanism in the 3-D Community Multiscale Air Quality (CMAQ) model, Atmos. Environ., 45, 3244-3256, 2011.

Zhang, X., Cappa, C. D., Jathar, S. H., McVay, R. C., Ensberg, J. J., Kleeman, M. J., and Seinfeld, J. H.: Influence of vapor wall loss in laboratory chambers on yields of secondary organic aerosol, P. Natl. Acad. Sci., 111, 5802-5807, 2014.

Zhao, B., Wang, S., Donahue, N. M., Chuang, W., Hildebrandt Ruiz, L., Ng, N. L., Wang, Y., and Hao, J.: Evaluation of OneDimensional and Two-Dimensional Volatility Basis Sets in Simulating the Aging of Secondary Organic Aerosol with SmogChamber Experiments, Environ. Sci. Technol., 49, 2245-2254, doi:10.1021/es5048914, 2015. 